MS17 Minerals, materials and polymorphs

\author{
Chairs: Håkon Hope, Elisa Nauha
}

\section{MS17-P1 Re-determination of four $\mathrm{CsCoPO}_{4}$ crystal structures from single-crystal X-ray diffraction data \\ Maria Orlova ${ }^{1}$, Hannes Krüger ${ }^{1}$, Volker Kahlenberg ${ }^{1}$, Dmitry Michailov $^{2}$, Albina Orlova ${ }^{2}$}

1. Institute of Mineralogy and Petrography, University of Innsbruck, Austria

2. Department of Chemistry, State University of Nizhny Novgorod, Russia

email: maria.p.orlova@gmail.com

The crystal structures of the four known $\mathrm{CsCoPO}_{4}$ polymorphs have been reported by $\mathrm{P}$. Henry [1] and $\mathrm{H}$. Kawaji [2]. The structures were determined using synchrotron (phase 1-4) and neutron powder diffraction (phase 3) methods. Although the reported structures are correct and are in good agreement with known structural analogues, for example, $\mathrm{CsZnPO}_{4}$, isotropic displacement parameters of some atoms seem to be questionable. For example, $\mathrm{B}$ of $\mathrm{P} 1$ of the phase 4 exhibits very low value of $0.3(1) \AA^{2}$. In order to understand the nature of low displacement parameters and to obtain more precise structural information for $\mathrm{CsCoPO}_{4}$ polymorphs, a single crystal diffraction study has been performed. The compound undergoes three phase transitions at following temperatures: $280,210,30^{\circ} \mathrm{C}$. It adopts two orthorhombic phases crystallizing in space group Pnma (phase 1) and Pn 2 a (phase 2), and two monoclinic phases, space group $P 12$ la 1 (phase 3) and $P 121$ (phase 4). New structural data of all four polymorphs with anisotropically refined displacement parameters will be presented and compared with known powder diffraction data. KEYWORDS Phosphates, Polymorphism, Crystal structure, Structure solution, Single-crystal diffraction

[1] P. Henry, E. Hughes, M. T. Weller, J. Chem. Soc., Dalton Trans.,2000, 555-558

[2] H. Kawaji, Y. Ishihara, A. Nidaira, et al., J. Therm Analys 92 2008, 451-455

The financial support of the Russian Science Foundation (Project No 16-13-10464) is gratefully acknowledged.

Keywords: Phosphates, Polymorphism, Crystal structure, Structure solution, Single-crystal diffraction

\section{MS17-P2 2D and 3D Titanium Phosphate Materials: Crystal Structure and Properties}

Santiago Garcia-Granda ${ }^{1}$, Jorge García-Glez ${ }^{2}$, Camino Trobajo Camino Trobajo ${ }^{2}$, Zakariae Amghouz ${ }^{3}$, Sergei A. Khainakov ${ }^{3}$, Conchi O. Ania ${ }^{4}$, José B. Parra ${ }^{4}$, Artem A. Babaryk ${ }^{5}$, Iván da Silva $^{6}$, Germán R. Castro ${ }^{7}$

1. Department of Physical and Analytical Chemistry, University of Oviedo-CINN, 33006 Oviedo, Spain

2. Department of Organic and Inorganic Chemistry, University of Oviedo-CINN, 33006 Oviedo, Spain

3. Scientific and Technical Services, University of Oviedo, 33006 Oviedo, Spain

4. INCAR-CSIC, 33080 Oviedo, Spain

5. Faculty of Chemistry, Taras Shevchenko National University of Kyiv, 01601 Kyiv, Ukraine

6. ISIS Facility, Rutherford Appleton Laboratory, Chilton, Oxfordshire OX110QX, UK

7. SpLine, Spanish CRG Beamline, ESRF, BP 220, 38043 Grenoble, France

email:sgg@uniovi.es

In 1990 Christensen et al. proposed the structure of titanium compound, $\mathrm{Ti}\left(\mathrm{PO}_{4}\right)\left(\mathrm{H}_{2} \mathrm{PO}_{4}\right) \cdot 2 \mathrm{H}_{2} \mathrm{O}$, according with Clayden, but later the combined ${ }^{2}$ SS-NMR and powder synchrotron X-ray diffraction data showed a different cell [1]. In 1995, the $\gamma$-ZrP was solved by Poojary et al., confirming the model reported by Christensen. Later, the $\beta$-TiP showed that the structure of the $\gamma$-type layer is retained in the anhydrous compound. Layered titanium phosphate compounds intercalated with amines may be used as precursors in pillaring reactions [2]. Despite the many potential applications of these materials, including the synthesis of organic-inorganic nanotubes [3], their detailed structural features have remained poorly understood. In the last decade, we have combined chemical information, NMR spectroscopy and powder XRD data, and chemical modeling studies to describe the alkylamine templated $\gamma$-titanium phosphates, including the $\left(\mathrm{C}_{2} \mathrm{H}_{5} \mathrm{NH}_{3}\right)\left[\mathrm{Ti}\left(\mathrm{H}_{15} \mathrm{PO}_{4}\right)\left(\mathrm{PO}_{4}\right)\right]_{2} \cdot \mathrm{H}_{2} \mathrm{O}$ pseudotridimensional porous structure (fibrous morphology) that shows an unusual and very strong interlayer-hydrogen bond [4].

Layered $\alpha$ - $\mathrm{Ti}\left(\mathrm{HPO}_{4}\right)_{2} \cdot \mathrm{H}_{2} \mathrm{O}(\alpha$-TiP) and its propylamine intercalation product, $\alpha$-Ti $\left(\mathrm{HPO}_{4}\right) \cdot 2 \mathrm{C}_{3} \mathrm{H}_{7} \mathrm{NH}_{2} \cdot \mathrm{H}_{2} \mathrm{O}$, have been synthesized and characterized, their sorption capacity for europium(III) was investigated, and structure of $\alpha$-[Eu( $\left.\left.\mathrm{H}_{2} \mathrm{O}\right)_{6}\right]_{2 / 3} \mathrm{Ti}\left(\mathrm{PO}_{4}\right)_{2} \cdot\left[\left(\mathrm{H}_{2} \mathrm{O}\right)_{6}\right]_{1 / 3}$, has been proposed by $\mathrm{DFT}$ calculations. ${ }^{2}$ Tri-dimensional $\mathrm{Ti}_{2} \mathrm{O}\left(\mathrm{PO}_{4}\right)_{2} \cdot 2 \mathrm{H}_{2} \mathrm{O}$ polymorphs $(\rho$-TiP and $\pi$-TiP) were prepared hydrothermally. The crystal structure of $\Pi$-phase was solved $a b$ initio from synchrotron data, and the thermal transformation of $\rho-\mathrm{Ti}_{2} \mathrm{O}\left(\mathrm{PO}_{4}\right) \cdot 2 \mathrm{H}_{2} \mathrm{O}$ to $\rho-\mathrm{Ti}_{2} \mathrm{O}\left(\mathrm{PO}_{4}\right)_{2}$, was monitored by HT-PXRD. The coordination ${ }^{2}$ environment of the hydrated titanium changes from octahedral to distorted tetrahedral, which explains the measurable thermally activated nitrogen-adsorption observed for the anhydrous phase. To our knowledge, the process described here constitutes the first example of nitrogen-fixation by an inorganic material far above room temperature.

Acknowledgments. Financial support from Spanish MINECO (MAT2013-40950-R), FICYT (GRUPIN14-060), and ERDF funding are acknowledged.

References [1] S. García-Granda, et al., Inorganic Chemistry 49 (2010) 2630-2638; [2] L. Mafra, et al., Chemistry of Materials 17 (2005) 6287-6294,; [3] J.A. 
Blanco, et al., Physica Status Solidi C 6 (2009) 2190-2194; [4] L. Mafra, et al., Chemistry of Materials 20 (2008) 3944-3953.

Keywords: Titanium, phosphate, crystallography
MS18 Structures of minerals,

planetary and carbon materials

at Earth and planetary

conditions
Chairs: Tiziana Boffa-Ballaran, Marco Merlini

\title{
amorphous silicates: the origin of cosmic carbonates?
}

\author{
Sarah J. Day ${ }^{1,2}$, Stephen P. Thompson ${ }^{1}$, Aneurin Evans ${ }^{2}$
}

\author{
1. Diamond Light Source \\ 2. Keele Univeristy
}

email: sjday15@googlemail.com

Silicates are the most abundant component of cosmic dust present in the universe, forming in the atmospheres of dying stars as primitive, structurally disordered grains. Throughout their lifetime dust grains are subjected to a number of physical processes leading to their evolution from highly disordered, refractory grains to the more complex crystalline mineral species that were present within the solar nebula. Of particular interest is the formation of crystalline Ca-rich carbonate minerals that have been identified in the spectra of evolved stars, protoplanetary disks and planetary nebulae [1]. Due to the absence of liquid water in these environments and that direct condensation of carbonates is unlikely, due their low condensation temperature [2] it is believed that carbonate species in such environments could form through solid-phase alteration of amorphous Ca-bearing silicates with gaseous $\mathrm{CO}_{2}$.

Amorphous cosmic silicate analogues are produced using a well-developed sol gel technique [3] in which the gels are dried under high-vacuum $\left(\sim 10^{-6} \mathrm{mbar}\right)$ to produce highly disordered, fine-grained powders of composition $\mathrm{Mg}_{(\mathrm{x})} \mathrm{Ca}_{(1-\mathrm{x})} \mathrm{SiO}_{3}$, where $0 \leq \mathrm{x} \leq 1$, analogous to the primitive silicates present within circumstellar and interstellar mediums [4]. Beamlines I11 and I12 at Diamond Light Source have been used to conduct synchrotron X-ray powder diffraction (SXPD) and Pair Distribution Function (PDF) measurements respectively, both in-situ and ex-situ. These measurements together provide an insight into the underlying structural mechanics that govern the carbonation reaction at the amorphous level as well as allowing a detailed study of the reaction kinetics and phase evolution.

The results of this research will be presented, focusing on the structural mechanisms involved with the carbonation of silicates in order to place constraints on the environmental conditions and initial silicate compositions favourable for carbonate formation.

\section{References}

